In those areas where denitrification is identified in this way (clusters of LNP points in Fig. 3) the denitrification may be occurring in the water column ${ }^{18,19}$ or within the sediment ${ }^{15,20}$, with subsequent exchange of substrates and products with the overlying waters. Open-ocean denitrification has been reported in the eastern tropical North Pacific ${ }^{21}$, the eastern tropical South Pacific ${ }^{14}$, and in the Arabian $\mathrm{Sea}^{22}$. Our criteria (equation (2)) identify the eastern tropical Pacific (north and south), but not the Arabian Sea. The Arabian Sea does not appear as a denitrification site because, although denitrification takes place, the nitrate:phosphate ratio does not fall much below 9.0 as a result ${ }^{22}$. In light of this, it is clear that the method used here will detect the majority of denitrificationaffected waters, but not all of them.

It has previously been suggested, from nitrogen deficit calculations, that denitrification is taking place within the northern North Pacific $^{23}$ and the Bering Sea ${ }^{24}$, but nevertheless these areas are not traditionally recognized as major sites of denitrification. The calculations reported here provide additional evidence for denitrification in these places, and additionally across large areas of the western North Pacific (Fig. 3). Nitrate concentrations are generally high ${ }^{4}$ and oxygen concentrations $\operatorname{low}^{25,26}$ in sub-surface waters in these areas, providing favourable conditions for denitrification ${ }^{27}$.

Assuming similar denitrification rates per unit area, the extent of the LNP points (Fig. 3 ) suggests that the total nitrate loss in the west and north North Pacific region is about 20\% higher than in the eastern tropical Pacific Ocean. Sedimentary denitrification contributes about half as much as water-column denitrification to the global flux ${ }^{20}$, and the eastern tropical Pacific (north and south) was previously estimated to contribute $\sim 85 \%$ of total water-column denitrification ${ }^{27}$. Therefore inclusion of the western and northern North Pacific could potentially increase the total global marine denitrification flux by about $70 \%$. This calculation is speculative, but it is clear that more detailed work should be carried out to enable more precise estimates to be made. Denitrification is the largest sink of reactive nitrogen from the oceans ${ }^{28,29}$, and is therefore a critical component in the global marine nitrogen cycle.

Received 12 August 1996; accepted 21 April 1997.

1. NODC World Ocean Atlas 1994 data set (http://www.nodc.noaa.gov/NODC-products.html).

2. Geochemical Oceans Section Study (GEOSECS) data set (http://ingrid.ldgo.columbia.edu/ SOURCES/.GEOSECS/).

Redfield, A. C. in James Johnston Memorial Volume 176-192 (Liverpool Univ. Press, 1934).

4. Levitus, S., Conkright, M. E., Reid, J. L., Najjar, R. G. \& Mantyla, A. Distribution of nitrate, phosphate and silicate in the world oceans. Prog. Oceanogr. 31, 245-273 (1993).

5. Anderson, L. A. On the hydrogen and oxygen-content of marine phytoplankton. Deep-Sea Res. I 42 1675-1680 (1995).

6. Copin-Montégut, C. \& Copin-Montégut, G. Stoichiometry of carbon, nitrogen, and phosphorous in marine particulate matter. Deep-Sea Res. 30, 31-46 (1983).

Smith, S. V. Phosphorus versus nitrogen limitation in the marine environment. Limnol. Oceanogr. 29, $1149-1160$ (1984).

8. Codispoti, L. A. in Productivity of the Ocean: Present and Past (eds Berger, W. H., Smetacek, V. S. \& Wefer, G.) 377-394 (Wiley, New York, 1989).

. Broecker, W. S. \& Peng, T.-H. Tracers in the Sea (Eldigio, New York, 1982).

10. Fanning, K. A. Nutrient provinces in the sea-concentration ratios, reaction-rate ratios, and ideal covariation. J. Geophys. Res. 97, 5693-5712 (1992).

11. Anderson, L. A. \& Sarmiento, J. L. Redfield ratios of remineralization determined by nutrient dataanalysis. Glob. Biogeochem. Cycles 8, 65-80 (1994).

12. Meybeck, M. in Interactions of C, N, P and S Biogeochemical Cycles and Global Change (eds Wollast, R. Mackenzie, F. T. \& Chou, L.) 163-193 (NATO ASI Ser., Vol. I 4, Springer, Berlin, 1993).

13. Kamykowski, D. \& Zentara, S.-J. Hypoxia in the world ocean as recorded in the historical data set. Deep-Sea Res. 37, 1861-1874 (1990)

14. Codispoti, L. A. \& Christensen, J. P. Nitrification, denitrification and nitrous oxide cycling in the eastern tropical South Pacific Ocean. Mar. Chem. 16, 277-300 (1985).

15. Canfield, D. E. in Interactions of C, N,P and S Biogeochemical Cycles and Global Change (eds Wollast, R., Mackenzie, F. T. \& Chou, L.) 333-363 (NATO ASI Ser., Vol. I 4, 1993).

16. Alldredge, A. L. \& Silver, M. W. Characteristics, dynamics and significance of marine snow. Prog. Oceanogr. 20, 41-82 (1988).

17. Kamykowski, D. \& Zentara, S.-J. Spatio-temporal and process-oriented views of nitrite in the world ocean as recorded in the historical data set. Deep-Sea Res. 38, 445-464 (1991).

18. Rönner, U. \& Sörensson, F. Denitrification rates in the low-oxygen waters of the Baltic proper. Appl. Environ. Microbiol. 50, 801-806 (1985).

19. Codispoti, L. A. et al. High nitrite levels off northern Peru: a signal of instability in the marine denitrification budget. Science 233, 1200-1202 (1986).

20. Christensen, J. P., Townsend, D. W. \& Montoya, J. P. Water column nutrients and sedimentary denitrification in the Gulf of Maine. Continent. Shelf Res. 16, 489-515 (1996).

21. Thomas, W. H. On denitrification in the northeastern tropical Pacific Ocean. Deep-Sea Res. 13, 1109 1114 (1966).

22. Mantoura, R. F. C. et al. Nitrogen biogeochemical cycling in the northwestern Indian Ocean. Deep-Sea Res. I 40, 651-671 (1993).
23. Tsunogai, S. in Biological Oceanography of the Northern North Pacific Ocean (eds Takenouti, A. Y. et al.) 517-533 (Idemitsu Shoten, Tokyo, 1972).

24. Tsunogai, S., Kusakabe, M., Iizumi, H., Koike, K. \& Hattori, A. Hydrographic features of the deep water in the Bering Sea—the sea of silica. Deep-Sea Res. 26, 641-659 (1979).

25. Levitus, S. \& Boyer, T. P. World Ocean Atlas 1994 Vol. 2, Oxygen (Atlas NESDIS 2, NOAA, Washington DC, 1994).

26. Ogura, N. Relation between dissolved organic carbon and apparent oxygen utilization in the Western North Pacific. Deep-Sea Res. 17, 221-231 (1970).

27. Hattori, A. in Nitrogen in the Marine Environment (eds Carpenter, E. \& Capone, D.) 191-232 (Academic, New York, 1983).

28. Jaffe, D. A. in Global Biogeochemical Cycles (eds Butcher, S. S., Charlson, R. J., Orians, G. H. \& Wolfe, G. V.) 263-284 (Academic, New York, 1992).

29. Mackenzie, F. T., Ver, L. M., Sabine, C., Lane, M. \& Lerman, A. in Interactions of C, N,P and S Biogeochemical Cycles and Global Change (eds Wollast, R., Mackenzie, F. T. \& Chou, L.) 1-61 (NATO ASI Ser., Vol. I 4, Springer, Berlin, 1993).

30. Conkright, M. E., Boyer, T. P. \& Levitus, S. Quality Control and Processing of Historical Nutrient Data (Tech. Rep. NESDIS 79, NOAA, Washington DC, 1994).

31. Press, W. H., Teukolsky, S. A., Vetterling, W. T. \& Flannery, B. P. Numerical Recipes in FORTRAN 2nd edn (Cambridge Univ. Press, 1992).

Acknowledgements. We thank D. Burton, C. Garside, D. Hydes and P. Wright for discussions; R. Mills, D. Hydes and M. Conkright for comments on the manuscript; and P. Challenor for sea-floor depth data.

Correspondence should be addressed to T.T. (e-mail: T.Tyrrell@soc.soton.ac.uk).

\section{Contrasting physiological and structural vegetation feedbacks in climate change simulations}

\section{Richard A. Betts ${ }^{\star}$, Peter M. Cox ${ }^{\star}$, Susan E. Lee $\dagger$ \& F. lan Woodward $\dagger$}

* Hadley Centre, Meteorological Office, Bracknell RG12 2SY, UK

$\dagger$ Department of Animal and Plant Sciences, University of Sheffield,

Sheffield S10 2TN, UK

Anthropogenic increases in the atmospheric concentration of carbon dioxide and other greenhouse gases are predicted to cause a warming of the global climate by modifying radiative forcing ${ }^{1}$. Carbon dioxide concentration increases may make a further contribution to warming by inducing a physiological response of the global vegetation-a reduced stomatal conductance, which suppresses transpiration ${ }^{2}$. Moreover, a $\mathrm{CO}_{2}$-enriched atmosphere and the corresponding change in climate may also alter the density of vegetation cover, thus modifying the physical characteristics of the land surface to provide yet another climate feedback ${ }^{3-6}$. But such feedbacks from changes in vegetation structure have not yet been incorporated into general circulation model predictions of future climate change. Here we use a general circulation model iteratively coupled to an equilibrium vegetation model to quantify the effects of both physiological and structural vegetation feedbacks on a doubled- $\mathrm{CO}_{2}$ climate. On a global scale, changes in vegetation structure are found to partially offset physiological vegetation-climate feedbacks in the long term, but overall vegetation feedbacks provide significant regionalscale effects.

The Sheffield University vegetation model simulates global vegetation under steady-state conditions of climate and atmospheric $\mathrm{CO}_{2}$ (ref. 7). It models the physiological processes of nutrient uptake, photosynthesis, respiration and stomatal limitation of transpiration, and uses these to determine the vegetation structural character in terms of foliage density. The outputs of this model are: (1) leaf area index (LAI), the area of leaf surface per unit area of ground; and (2) daytime mean canopy conductance $\left(g_{\mathrm{c}}\right)$, the net transpirational conductance of all stomata integrated (numerically) over the canopy depth. LAI is purely a structural variable, whereas $g_{c}$ contains both structural and physiological contributions. The 
contemporary vegetation simulation has been validated against point measurements.

The Hadley Centre general circulation model (GCM) used here is a simplified version of that used for climate change prediction ${ }^{8,9}$, consisting of an explicit representation of the global atmospheric circulation and a thermodynamic 'mixed-layer' ocean model with prescribed heat transports to represent ocean currents ${ }^{10}$. The simulations presented here neglect the relative cooling effect of increased sulphate aerosol concentrations ${ }^{8}$; this omission and that of explicit ocean current modelling means that the results cannot be regarded as a state-of-the-art prediction. Instead, they demonstrate the effect of vegetation feedback on climate sensitivity to atmospheric $\mathrm{CO}_{2}$ concentrations.

The GCM land surface scheme is of moderate complexity ${ }^{11}$, with the land surface state defined by seven prognostic variables: rootzone soil moisture, lying snow, intercepted canopy water, and the temperatures of four soil layers in the vertical. The surface energy partitioning, evapotranspiration, runoff and snowmelt are parametrized using driving variables from the atmosphere model and seven vegetation-specific land surface parameters ${ }^{3}$. The main parameters are: root depth, determining the depth of soil from which water can be extracted for transpiration; snow-free and deep-snow albedos, determining the fraction of incident solar radiation reflected from the surface; roughness length, determining the aerodynamic resistance for turbulent transfers; and surface conductance, determining the additional resistance for water vapour transfers in drought-free conditions. Over vegetated surfaces, the latter accounts for the control of transpiration by stomata, but is a prescribed vegetation-specific constant in this version of the scheme.

The GCM and vegetation model were coupled by iterating between the two models, each providing boundary conditions for the other. The GCM supplied climatological monthly means to the
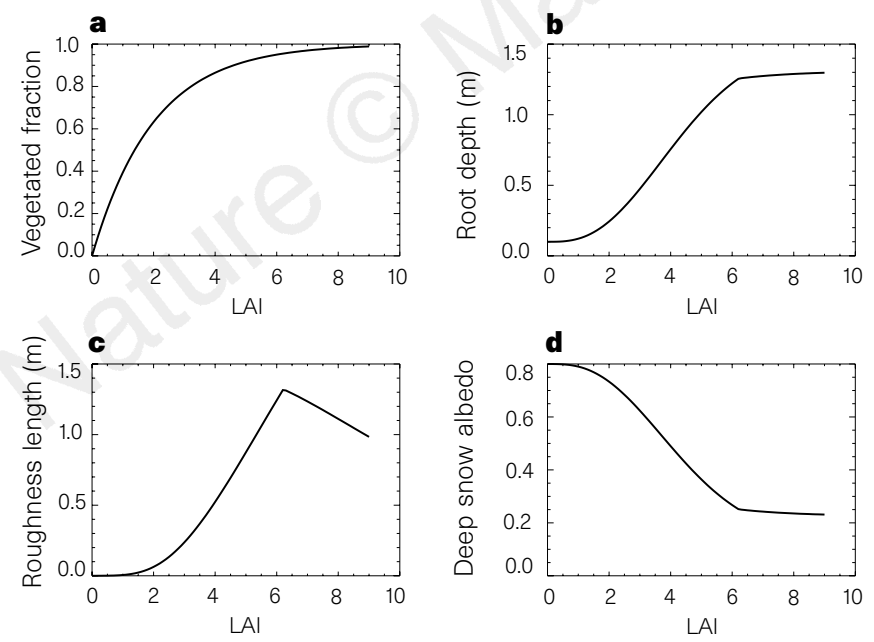

Figure 1 Derivation of GCM land surface parameters from leaf area index (LAI). a, Vegetated fraction is the fractional ground area covered by vegetation; this determines the relative weighting of values appropriate to vegetation and soil for the other variables. An empirical fit with the literature data ${ }^{16-18}$ shows that vegetated fraction increases with $L A I$, saturating at higher values. $\mathbf{b}$, The mean root depth is found empirically ${ }^{16-20}$ to increase with $L A l$ in the grid-box mean, and is also assumed to be linearly correlated with the maximum infiltration rate at the soil surface. c, Roughness length increases with LAl at low leaf areas, but decreases with $L A l$ at higher values as the canopy becomes closed ${ }^{21}$. d, Deepsnow albedo ${ }^{17}$ is the upper limit of surface reflectance in deep-snow conditions, and this decreases with LAl as more of the snow is masked by the darker vegetation. Snow-free albedo shows a similar but less pronounced relationship. vegetation model, which returned the global distributions of LAI and $g_{c}$. The latter were used to redefine the GCM land surface parameters for the next iteration, with surface conductance incorporating $g_{c}$ directly, and the remaining structural parameters being derived semi-empirically from LAI (Fig. 1).

The physiological and structural vegetation feedbacks on $\mathrm{CO}_{2^{-}}$ induced climate change were isolated and quantified using the following four coupled simulations. (1) Both climate and vegetation consistent with an atmospheric $\mathrm{CO}_{2}$ concentration of 323 parts per million by volume, p.p.m.v. $\left(1 \times \mathrm{CO}_{2}\right.$; simulation $\left.\mathrm{C}\right)$. (2) The climate at equilibrium under $2 \times \mathrm{CO}_{2}$ (646 p.p.m.v.) radiative forcing, but with the physiological and structural characteristics of the vegetation held at the $1 \times \mathrm{CO}_{2}$ state (simulation $\mathrm{R}$ ). (3) $2 \times \mathrm{CO}_{2}$ radiative forcing and $1 \times \mathrm{CO}_{2}$ vegetation structure, but with surface conductance including direct effects of $2 \times \mathrm{CO}_{2}$ and the associated climate change on plant physiology (simulation RP). (4) $2 \times \mathrm{CO}_{2}$ radiative forcing with both the physiology and structure allowed to reach a new equilibrium state under $2 \times \mathrm{CO}_{2}$ and the associated climate (simulation RPS).

The difference between simulations $\mathrm{R}$ and $\mathrm{C}$ represents the standard GCM sensitivity to $\mathrm{CO}_{2}$ excluding vegetation feedbacks, and the difference between RP and $\mathrm{R}$ defines the additional climate change resulting from the direct physiological effects (a comparable experiment to that in ref. 2). Finally, the difference between RPS and $\mathrm{R}$ demonstrates the combined effect of physiological and structural vegetation change on the climate sensitivity; this is the main new result of this work.

The radiation-only $2 \times \mathrm{CO}_{2}$ sensitivity $(\mathrm{R}-\mathrm{C})$ of this version of the GCM was $4.3 \mathrm{~K}$, which is at the high end of the IPCC range ${ }^{1}$. The modelled climate change showed relatively large changes in temperature and precipitation in the tropics (Fig. 2), associated with strong cloud-mediated feedbacks. The physiological response in

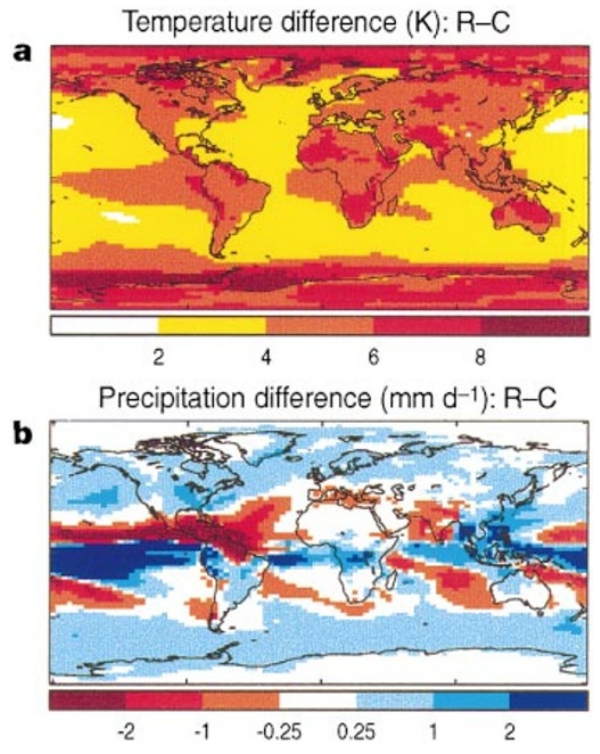

Figure 2 Climate change due to doubling the atmospheric concentration of $\mathrm{CO}_{2}$, neglecting vegetation feedback, expressed as differences between simulations $\mathrm{R}$ and $\mathrm{C}$ (see text). a, Change in annual mean temperature, diagnosed at a height of $1.5 \mathrm{~m}$ above the surface. $\mathbf{b}$, Change in annual mean precipitation. 
Key to simulations

$\mathrm{R}: 2 \mathrm{xCO}_{2}$ radiation

RP : $2 \times \mathrm{CO}_{2}$ radiation + physiological feedback

RPS : $2 \times \mathrm{CO}_{2}$ radiation + physiological \& structural feedback

\section{Physiology only}

Conductance difference $\left(\mathrm{mm} \mathrm{s}^{-1}\right)$ : RP-R

a

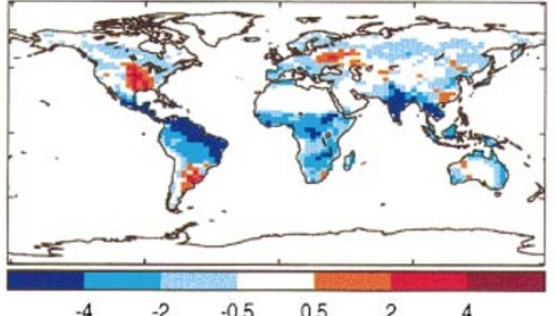

Temperature difference $(\mathrm{K})$ : RP-R

b

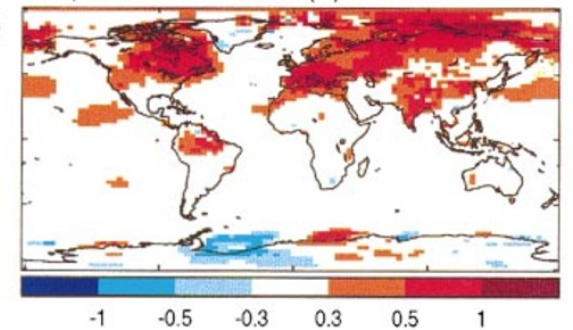

Evaporation difference $\left(\mathrm{mm} \mathrm{d}^{-1}\right)$ : RP-R

c

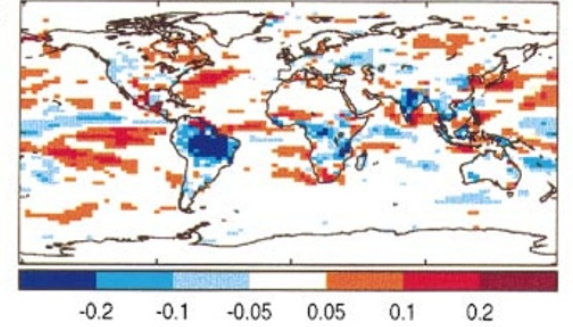

\section{Physiology and structure}

Leaf area index difference : RPS-R

d

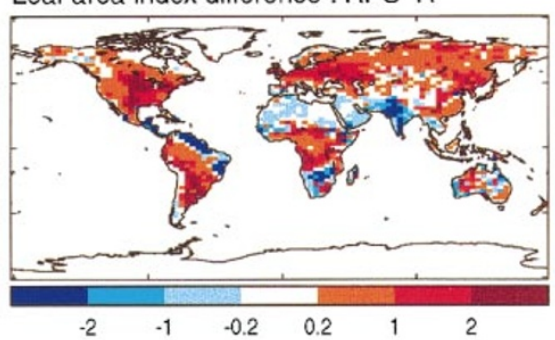

Conductance difference (mm s-1): RPS-R

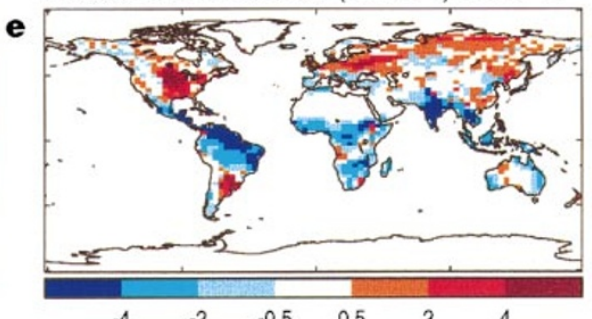

Temperature difference $(K)$ : RPS-R

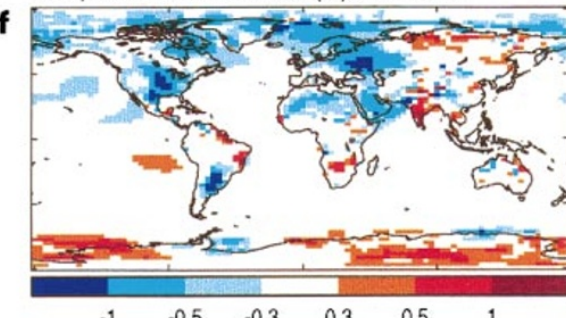

\section{Evaporation difference $\left(\mathrm{mm} \mathrm{d}^{-1}\right)$ : RPS-R}

g

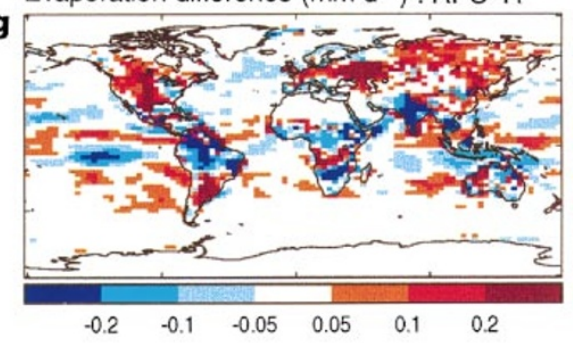

Figure 3 Physiological and structural vegetation change under doubled atmospheric $\mathrm{CO}_{2}$ concentration $\left(2 \times \mathrm{CO}_{2}\right)$, and feedback of each on $2 \times \mathrm{CO}_{2}$ climate. $\mathbf{a}$, Change in canopy conductance due to physiological response to $2 \times \mathrm{CO}_{2}$ and the associated climate change. $\mathbf{b}$, Effect of physiological feedback on $2 \times \mathrm{CO}_{2}$ temperature. c, Effect of physiological feedback on $2 \times \mathrm{CO}_{2}$ evaporation. d, Change in leaf area index due to structural response to $2 \times \mathrm{CO}_{2}$ and the associated climate change. e, Change in canopy conductance due to both physiological and structural response. f, Combined effect of both physiological and structural feedback on $2 \times \mathrm{CO}_{2}$ temperature. g, Combined effect of both physiological and structural feedback on $2 \times \mathrm{CO}_{2}$ evaporation. $40 \%$ of the land surface experienced vegetation feedbacks on temperature (RPS - R) of at least $5 \%$ of the magnitude of the changes due to radiative forcing alone $(R-C) .13 \%$ of the land showed relative temperature feedbacks of $10 \%$ or more. The relative evaporation feedbacks were larger and more widespread, with $74 \%$ of the land surface having a relative feedback of $10 \%$ or more, and $30 \%$ showing a feedback of over $50 \%$. Vegetationinduced evaporation changes were larger than the greenhouse-gas-only changes for $18 \%$ of the land surface. Calculation of $t$-statistics for grid-point annual means showed that most temperature changes of $0.5 \mathrm{~K}$ or more were significant at the $1 \%$ confidence level or better. The exceptions to this were in the polar and sub-polar regions, where significance was reduced by higher interannual variability. In Siberia, temperature changes of $0.5 \mathrm{~K}$ were significant at $5 \%$ or better, while in Antarctica and the Arctic Ocean, little of the temperature change was significant at better than $20 \%$. Almost all land evaporation changes of $0.1 \mathrm{~mm} \mathrm{~d}^{-1}$ were significant at $1 \%$. simulation RP was a general reduction in $g_{c}$ relative to simulation $\mathrm{R}$ (Fig. 3a), consistent with increased water-use efficiency under $2 \times \mathrm{CO}_{2}$. Some areas with modified hydrological regimes experienced $g_{c}$ increases caused by increased humidity, but the global mean change was a reduction of $\sim 20 \%$ (Table 1 ). These caused significant feedbacks on climate $(\mathrm{RP}-\mathrm{R})$, with temperature increasing by up to $1 \mathrm{~K}$ over Northern Hemisphere land (Fig. 3b). The large conductance decreases in the tropical forests produced small temperature changes but appreciable reductions in evapotranspiration (Fig. 3c). The modelled effects of physiology on mean land temperature, evapotranspiration and conductance are all in close agreement with those from a previous study ${ }^{2}$.

The structural response in simulation RPS was a widespread increase in LAI relative to simulation R (Fig. 3d), due to increased productivity and water-use efficiency under the new $\mathrm{CO}_{2}$ concentration and climate. The greatest LAI increases were in regions of increased rainfall. These changes acted to offset the physiological reductions in conductance, and at high latitudes the result was an overall increase in $g_{c}$ (Fig. 3e); this is contrary to the result obtained when allowing physiological change alone (Fig. 3a). Elsewhere, the reduced $g_{c}$ seen in simulation RP also occurred in simulation RPS; the reductions were smaller than in $\mathrm{RP}$, except in regions where significantly reduced rainfall (Fig. 2b) had caused conspicuous reductions in LAI (Fig. 3d). The combined effect of physiology and structure was a reduction of $\sim 12 \%$ in $g_{c}$ in the global mean (Table 1), which is considerably less than the reduction due to physiology alone.

The combined physiological and structural vegetation feedbacks had significant effects on the climate sensitivity (RPS - R; Fig. 3f,g). Structural changes acted via two competing effects; increased LAI tended to warm the land surface by lowering its albedo ${ }^{4-6}$ and to cool the land surface by enhancing evaporation (and consequently cloud cover ${ }^{12,13}$ ) via increases in root depth ${ }^{14}$, roughness length ${ }^{15}$ and surface conductance. Similarly, decreased LAI tended to cool the surface via increased albedo, and warm the surface via reduced evaporation. The albedo effect dominated in regions where the vegetation was sparse, or where the underlying surface was much more reflective than the vegetation such as in snow-covered regions ${ }^{4-6}$; however, the evaporation effect dominated elsewhere. Temperature changes (Fig. 3f) were therefore negatively correlated with LAI changes (Fig. 3d), except in sparsely vegetated regions and also northern Siberia, where greater LAI caused a warming via 


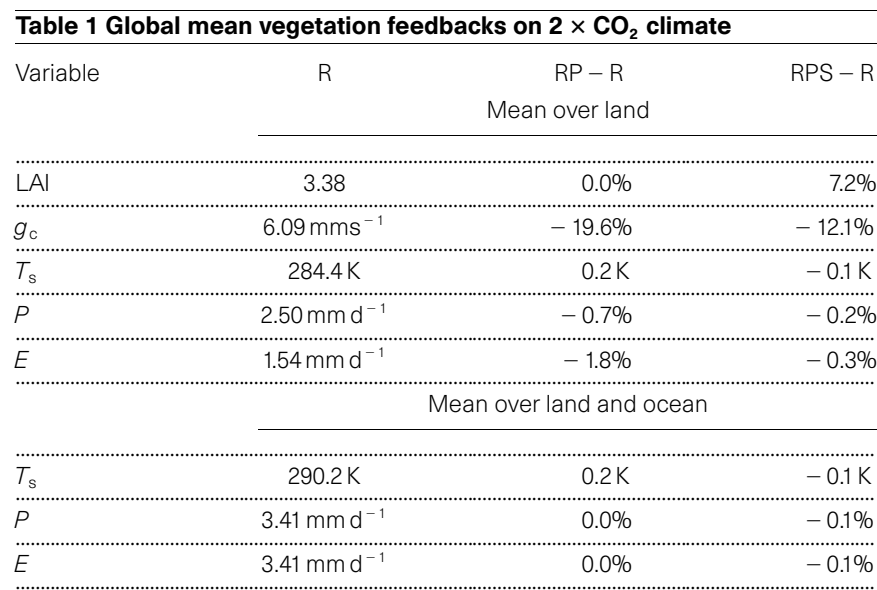

Mean values and perturbations to leaf area index (LAl), canopy conductance $\left(g_{\mathrm{c}}\right)$, screenlevel temperature $\left(T_{\mathrm{s}}\right)$, total precipitation $(P)$ and total surface moisture flux $(E)$. Column 2 shows absolute values for simulation $\mathrm{R}$ (radiation only), column 3 shows the changes due to the physiological response only (RP $-\mathrm{R})$, and column 4 gives the total vegetation feedback (RPS - R). Changes are given as percentages of the value in simulation $R$, except for temperature changes which are given in $\mathrm{K}$.

increased masking of snow. The feedback through evaporation was significantly modified by structural changes, especially in the middle- and high-latitude regions (compare Fig. $3 \mathrm{c}$ and g). However, transpiration from the tropical rainforests, which experienced negligible changes in LAI, was still significantly reduced compared to simulation $\mathrm{R}$.

It is important to recognize that changes in vegetation structure may lag the physiological response to increased $\mathrm{CO}_{2}$ by several years or even decades. Therefore, the actual effect of vegetation feedback on climate at the time of $\mathrm{CO}_{2}$ doubling is likely to lie somewhere between the results of simulations RP and RPS. A full assessment of this will require a model of vegetation dynamics fully integrated within a GCM. Nevertheless, our results show that changes in land surface properties due to vegetation can provide climatic feedback mechanisms that are both positive and negative in relation to climate change due to radiative forcing alone; furthermore, they demonstrate that the sign of the feedback depends partly on whether local vegetation growth is enhanced or suppressed by increased $\mathrm{CO}_{2}$ concentration and the associated climate change, and partly on the nature of the locally dominant surface-atmosphere interaction. Both physiological and structural characteristics of the vegetation have been shown to be important, with changes in one property often counteracting changes in another. In the global mean, the competing effects of increased water use efficiency and increased LAI cause a small surface evaporation change relative to the climate change simulation with fixed vegetation properties. We conclude that a short-term enhancement of regional climate warming by vegetation physiology may eventually be mitigated by a longer term modification of surface characteristics due to vegetation morphology. As this work does not account for the timescales involved in the full suite of vegetation feedbacks, the next stage should be to include dynamical changes in both vegetation physiology and structure in GCM predictions of future climate change.

Received 28 October 1996; accepted 28 April 1997

1. Houghton, J. T. et al. (eds) Climate Change 1995 (Cambridge Univ. Press, 1995).

2. Sellers, P. J. et al. Comparison of radiative and physiological effects of doubled atmospheric $\mathrm{CO}_{2}$ on climate. Science 271, 1402-1406 (1996).

3. Lean, J. \& Rowntree, P. R. A GCM simulation of the impact of Amazonian deforestation on climate using an improved canopy representation. Q. J. R. Meteorol. Soc. 119, 509-530 (1993).

4. Bonan, G. B., Pollard, D. \& Thompson, S. L. Effects of boreal forest vegetation on global climate Nature 359, 716-718 (1992)

5. Foley, J. A., Kutzbach, J. E., Coe, M. T. \& Levis, S. Feedbacks between climate and boreal forests during the Holocene epoch. Nature 371, 52-54 (1994).

6. Gallimore, R. G. \& Kutzbach, J. E. Role of orbitally induced changes in tundra area in the onset of glaciation. Nature 381, 503-505 (1996).

7. Woodward, F., Smith, T. M. \& Emanuel, W. R. A global land primary productivity and phytogeography model. Glob. Biogeochem. Cycles 9, 471-490 (1995).
8. Mitchell, J. F. B., Johns, T. C., Gregory, J. M. \& Tett, S. F. B. Climate response to increasing levels of greenhouse gases and sulphate aerosols. Nature 376, 501-504 (1995).

9. Jones, R. G., Murphy, J. M. \& Noguer, M. Simulation of climate change over Europe using a nested regional-climate model. I: Assessment of control climate, including sensitivity to location of lateral boundaries. Q. J. R. Meteorol. Soc. 121, 1413-1449 (1995).

10. Senior, C. A. \& Mitchell, J. F. B. Carbon dioxide and climate: the impact of cloud parameterization. J. Clim. 6, 393-418 (1993)

11. Chen, T. H. et al. Cabauw experimental results from the project for intercomparison of land-surface schemes (PILPS). J. Clim. (in the press).

12. Rowntree, P. R. \& Bolton, J. A. Simulation of the atmospheric response to soil moisture anomalies over Europe. Q. J. R. Meteorol. Soc. 109, 501-526 (1983).

13. Beljaars, A. C. M., Viterbo, P., Miller, M. J. \& Betts, A. K. The anomolous rainfall over the United States during July 1993: sensitivity to land surface parameterization and soil moisture anomalies. Mon. Weath. Rev. 124, 362-383 (1996).

14. Milly, P. C. D. \& Dunne, K. A. Sensitivity of the global water cycle to the water-holding capacity of land. J. Clim. 7, 506-526 (1994).

15. Rowntree, P. R. in Land Surface Evaporation (eds Schmugge, T. J. \& Andre, J. C.) 5-30 (Springer, New York, 1991).

16. Wilson, M. F. \& Henderson-Sellers, A. A global archive of land cover and soils data for use in general circulation climate models. J. Climatol. 5, 119-143 (1985)

17. Sellers, P. J., Mitz, Y., Sud, Y. C. \& Dalcher, A. A simple biosphere model (SiB) for use within general circulation models. J. Atmos. Sci. 43, 505-531 (1986).

18. Lowry, W. P. \& Lowry, P. P. Fundamentals of Biometeorology. Interactions of Organisms and the Atmosphere Vol. 1 (Peavine, McMinnville, OR, 1989).

19. Eagleson, P. S. Dynamic Hydrology (McGraw Hill, New York, 1970).

20. Halldin, S., Saugier, B. \& Pontailler, F. Y. Evapotranspiration of a deciduous forest. Simulation using routine meteorological data. J. Hydrol. 75, 323-341 (1984).

21. Shaw, R. H. \& Pereira, A. R. Aerodynamic roughness of a plant canopy. Agricult. Meterol. 26, 51-65 (1982).

Acknowledgements. We thank E. M. Blyth, J. Foley, R. J. Harding, W. J. Ingram, J. E. Lovelock, J. F. B. Mitchell, P. L. Mitchell, P. R. Rowntree, C. A. Senior, W. J. Shuttleworth, S. F. B. Tett and P. J. Valdes for comments, advice and discussion. This work was supported by the NERC TIGER programme and the UK Department of the Environment.

Correspondence and requests for materials should be addressed to R.A.B. (e-mail: rabetts@meto.gov.uk)

\section{Wing upstroke and the evolution of flapping flight}

\section{Samuel O. Poore, A. Sánchez-Haiman \& G. E. Goslow Jr}

Department of Ecology and Evolutionary Biology, Brown University, Providence, Rhode Island 02912, USA

Movements of the wing during upstroke in birds capable of powered flight are more complex than those of downstroke $\mathrm{e}^{1-3}$. The m. supracoracoideus (SC) is a muscle with a highly derived morphology that is generally considered to be the primary elevator of the wing $^{4-6}$. This muscle arises from the ventrally oriented sternum and its tendon of insertion passes craniodorsally through a special bony canal, around a bony process which deflects it laterally, to attach on the dorsal aspect of the humerus above the glenohumeral joint (Fig. 1). We studied the contractile properties of the SC in situ and related them to wing kinematics in the European starling (Sturnus vulgaris). Our findings indicate that the primary role of the SC is to impart a high-velocity rotation about the longitudinal axis of the humerus. This rapid 'twisting' of the humerus, coupled with limited humeral elevation, is responsible for positioning the forearm and hand so that their subsequent extension orients the outstretched wing appropriately for the following downstroke. This reinterpretation of the primary function of the SC provides insight into the selective advantage of its unique musculoskeletal organization in the evolution of powered flapping flight in birds.

A general feature of powered locomotion based on an oscillating wing is an asymmetry in how the wing meets the environment during the downstroke compared with the upstroke parts of the wingbeat cycle $^{7}$. The downstroke in birds, when primary lift and propulsion are achieved, is characterized by an outstretched wing. The more complicated upstroke involves rapid withdrawal of the wing towards the body to reduce its surface area, elevation and subsequent extension in a way that minimally retards lift and thrust gained in the previous downstroke. The distinct musculoskeletal configuration of the $\mathrm{m}$. supracoracoideus (SC) was not present in 